\title{
Quench-aging of Niobium-Hydrogen Alloys at $-196^{\circ} \mathrm{C}^{*}$
}

\author{
By Yasuo Sasaki** and Muneyuki Amano**
}

\begin{abstract}
A decrease in electrical resistivity of niobium-hydrogen alloys is observed during the isothermal aging at $-196^{\circ} \mathrm{C}$. It is shown that the aging process is a reaction with the time exponent of $1 / 3$ and the activation energy of $0.10 \pm 0.02 \mathrm{eV}$. A change in flow stress is also observed with the aging at this temperature. These phenomena are not found in hydrogen-free niboium. It is suggested that the changes in resistivity and flow stress should be attributed to the hydride precipitation at $-196^{\circ} \mathrm{C}$.
\end{abstract}

(Received June 8, 1968)

\section{Introduction}

It has been reported that some physical and mechanical properties of niobium are affected by the addition of hydrogen. Borgucci and Verdini(1) measured the electrical resistivity of niobium containing hydrogen of low concentration and reported that the resistivity increment caused by the addition of hydrogen was about $0.75 \mu \Omega \mathrm{cm} /$ at\% hydrogen. Wilcox and Huggins( $\left.{ }^{2}\right)$ studied the strain aging process of hydrogenated niobium using yield point return and dynamic modulus measurements, and concluded that hydrogen as solute could be responsible for dislocation locking in niobium.

Zamir and Cotts ${ }^{(3)}$ observed the nuclear magnetic resonances of hydrogen and niobium in the $\mathrm{Nb}-\mathrm{H}$ system as functions of hydrogen concentration and temperature. They found a sharp change in the hydrogen diffusion rate and concluded that this was associated with the phase transition at temperatures between $60^{\circ}$ and $100^{\circ} \mathrm{C}$. They also obtained the activation energy of $0.16 \mathrm{eV}$ for the diffusion of hydrogen in niobium. Albrecht et al. (4) investigated the reaction of hydrogen gas with niobium by the absorption method and found the activation energy for the diffusion of hydrogen in niobium to be $0.41 \mathrm{eV}$. The activation energy obtained by the absorption method sharply disagreed with those of Zamir and Cotts ${ }^{(3)}$.

Niobium metal reacts with hydrogen exothermally and forms hydride. Walter and Chandler(5) offered a $\mathrm{Nb}-\mathrm{H}$ phase diagram for the hydrogen concentrations up to 47.7 at\% at temperatures below $204.4^{\circ} \mathrm{C}$. The homogeneity range of hydride was found to be between

* This paper was presented at the Spring Meeting of the Japan Institute of Metals, Apr. 7, 1967, Tokyo, Japan.

** National Research Institute for Metals, Tokyo, Japan.

(1) M. N. Borgueci and L. Verdini : phys. stat. sol., 9 (1965), 243

(2) B. A. Wilcox and R. A. Huggins : J. Less-Common Metals, 2 (1960), 292.

(3) D. Zamir and R. M. Cotts : Phys. Rev., 134 (1964), A666.

(4) W. M. Albrecht, W. D. Goode and M. W. Mallet : J. Electrochem. Soc., 106 (1959), 981.

(5) R. J. Walter and W. T. Chandler : Trans. ATME, 233 (1965), 762.

Trans. J I M
41 at\% and 50 at\% hydrogen. The maximum solid solubility of hydrogen in niobium was about 9.1 at\% at the eutectoid temperature $\left(=73.9^{\circ} \mathrm{C}\right)$. The solubility limit showed a marked decrease at lower temperatures. All the above experiments were carried out at or above room temperature.

It is necessary to study the behavior of hydrogen in niobium at low temperatures in order to obtain a clearer picture of the hydrogen-metal relationship.

In the present work, the electrical resistivity and the mechanical property of niobium-hydrogen alloys were investigated during the course of aging at $-196^{\circ} \mathrm{C}$.

\section{Experimental Procedure}

\section{Specimen preparation}

The material used for experiments was obtained from Kawecki Chemical Co. in the form of a recrystallized wire $(0.5 \mathrm{~mm} \phi)$ with a mean grain diameter of $0.05 \mathrm{~mm}$. The composition of the material as-received is shown in the footnote*. The wire was first heattreated at $1000^{\circ} \mathrm{C}$ for $2 \mathrm{hr}$ in a vacuum of $3 \times 10^{-5}$ $\mathrm{mmHg}$, so as to eliminate hydrogen in the material. The resistance ratio, $R_{25 \circ \mathrm{c}} / R_{-196}{ }^{\circ}$, of the heat-treated wire was 4.83 and its resistivity at $-196^{\circ} \mathrm{C}$ was $3.17 \mu \Omega$ cm.

Hydrogen charging was performed by the gas exposure method and the electrolytic method. The gas exposure was carried out in 1 atm pressure of palladium-purified hydrogen at various temperatures between $500^{\circ}$ and $900^{\circ} \mathrm{C}$. Specimens were exposed in a furnace and cooled rapidly to avoid the excess absorption of hydrogen which would occur by slow cooling in hydrogen. Slight contamination with impurities (nitrogen and oxygen) was unavoidable and the contamination during exposure was about $100 \mathrm{ppm}$. Niobium-2.8 at\% hydrogen and niobium-4.9 at\% hydrogen alloys were prepared by this method.

The electrolytic method was also used for hydrogen charging in order to avoid contamination by im-

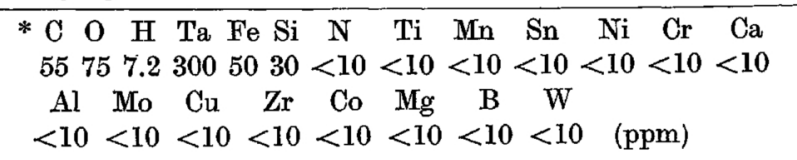

1969 Vo1. 10 
purities ${ }^{(6)}$. Hydrogen was introduced by this method using a niobium wire $120 \mathrm{~mm}$ long as a cathode and a platinum wire as an anode. A solution containing 69.8 vol\% $\mathrm{CH}_{3} \mathrm{OH}, 27.8$ vol\% $\mathrm{H}_{2} \mathrm{O}$ and 2.4 vol\% $\mathrm{H}_{2} \mathrm{SO}_{4}$ was used as an electrolyte. The current density of $35 \mathrm{~mA} / \mathrm{cm}^{2}$ was chosen and the charging period was varied. In this method, the possibility of a non-uniform distribution of hydrogen was considered to take place in the cross section of the specimen. These specimens were annealed at $100^{\circ} \mathrm{C}$ for $1 \mathrm{hr}$ in boiling distilled water to homogenize the hydrogen distribution. As the non-uniform distribution of hydrides in high esncentration alloys was treated similarly, it was considered that this heat treatment was sufficient to ensure an uniform distribution of hydrogen. Niobium-0.8 at\% hydrogen alloy was prepared by electrolytic charging.

Hydrogen analyses were performed by the vacuum extraction method. The hydrogen contents in the specimens charged by the electrolytic method were also determined from the weight difference before and after charging, and they were in good agreement with those from the vacuum extraction method.

\section{Measurements of electrical resistivity}

Resistance of the hydrogenated specimen $(0.5 \mathrm{~mm} \phi \times$ $60 \mathrm{~mm}$ ) was measured with a Yokogawa P7-B type potentiometer and the error of resistivity measurements was less than $\pm 2 \times 10^{-10} \mathrm{ohm} \mathrm{cm}$. Potential and current leads $(0.3 \mathrm{~mm} \phi)$ of gold wire were fixed on the specimen by spot welding. The leads were clamped with copper screw terminals in a specimen holder. The terminals and the specimen holder were immersed in stirred liquid nitrogen, liquid argon or liquid oxygen for resistivity measurement. Slight fluctuations in temperatures of the liquid gases were corrected by a dummy specimen. The dummy of annealed hydrogen-free niobium wire was kept in the liquid gas throughout the resistivity measurement for the correction of temperature variations.

The differential resistometric analyses were carried out at a rate of temperature rise of $0.2^{\circ} \mathrm{C} / \mathrm{min}$ from $-196^{\circ} \mathrm{C}$, by a simultaneous measurement of the resistivities of hydrogenated niobium and hydrogenfree niobium. A copper-constantan thermocouple was fitted in the specimen holder and the electric power input was controlled.

\section{Mechanical tests}

Tensile straining was made in an Instron-type testing machine at a strain rate of $8.33 \times 10^{-4} \mathrm{sec}^{-1}$. Samples were $20 \mathrm{~mm}$ long, $10 \mathrm{~mm}$ in gauge length and $0.5 \mathrm{~mm}$ in diameter. Quench-aging and mechanical tests were carried out at $-196^{\circ} \mathrm{C}$ as follows: the gripholders connected with a load cell and a crosshead were pre-cooled in liquid nitrogen. After grips and the specimen arranged at $25^{\circ} \mathrm{C}$ were quickly placed in the holders, the holders with the specimen were dipped in liquid nitrogen again. The specimens were aged at $-196^{\circ} \mathrm{C}$ for various periods and stretched by the machine at this temperature.

(6) Y. Sasaki and M. Amano : Trans. JIM, 8 (1967), 276.

\section{Results}

\section{Electrical resistivity}

Differential resistometric analyses were carried out and the results obtained in niobium-2.8 at\% hydrogen and 0.8 at\% hydrogen alloys are given in Fig. 1. Differences in resistivity $\left(\Delta \rho=\rho_{\mathrm{Nb}-\mathrm{H}}-\rho_{\mathrm{Nb}}\right)$ between alloys and hydrogen-free niobium are plotted by the open circles as a function of temperature. The inflection temperatures of $25 \pm 2{ }^{\circ} \mathrm{C}$ and $0 \pm 2{ }^{\circ} \mathrm{C}$ shown by the arrows in Fig. 1 are considered to be the terminal solid solubility temperatures. The results presented here were obtained during heating. The possibility of a heating-cooling hysteresis was examined subsequently. In the cooling experiment of niobium2.8 at\% hydrogen alloy, the temperature at which the inflection point occurred in the temperature range $100^{\circ}$ to $5^{\circ} \mathrm{C}$ was in good agreement with that obtained during heating.

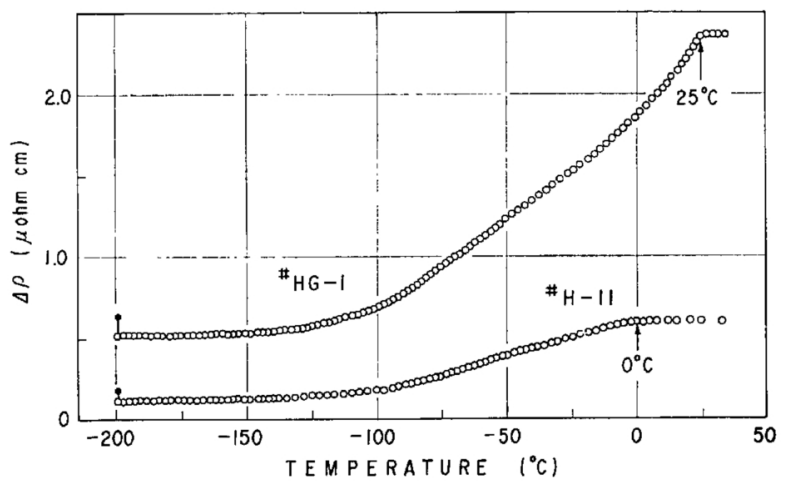

Fig. 1 Differences in resistivity $\left(\Delta \rho=\rho_{N} b-H-\rho_{N b}\right)$ between hydrogen-free niobium and niobium- 0.8 at\% hydrogen $(\# \mathrm{H}-11)$ or niobium-2.8 at\% hydrogen ( $\$ \mathrm{HG}-1)$ alloy in differential resistometric analyses. In the specimens quenched to $-196^{\circ} \mathrm{C}$ from $25^{\circ} \mathrm{C}$ and aged at $-196^{\circ} \mathrm{C}$ for $1 \mathrm{~min}, \Delta \rho$ are shown by closed circles and $\Delta \rho$ decrease along solid lines during the aging at $-196^{\circ} \mathrm{C}$

In the specimens quenched from $25^{\circ} \mathrm{C}$ to $-196^{\circ} \mathrm{C}$ and aged for $1 \mathrm{~min}$ at this temperature, $\Delta \rho$ are shown by the closed circles in Fig. 1. On aging at $-196^{\circ} \mathrm{C}$, $\Delta \rho$ of these specimens decrease along the solid lines. $\mathrm{A}$ similar decrease in resistivity was also observed in niobium-4.9 at\% hydrogen alloy.

The specimens, which exhibited a constant value of resistivity after a prolonged aging of more than $1 \times$ $10^{4} \mathrm{~min}$ in liquid nitrogen, were pulse-annealed at $-85^{\circ} \mathrm{C}$ for $1 \mathrm{~min}$ and then aged again in liquid nitrogen, liquid argon or liquid oxygen. The pulseannealing was carried out in an iso-pentane bath controlled at $-85.0 \pm 0.1^{\circ} \mathrm{C}$. The resistivity decreased during the aging and attained a constant value of $\rho(\infty)$, after $1 \times 10^{4} \mathrm{~min}, 2 \times 10^{3} \mathrm{~min}$ and $1 \times 10^{3} \mathrm{~min}$ aging in liquid nitrogen, liquid argon and liquid oxygen, respectively. Each isothermal aging curve showed a linear relationship between the resistivity $\rho(t)$ at time $t$ and $\log (t)$ at the initial stage of aging. An isothermal aging curve of niobium-0.8 at\% hydrogen alloy at $-196^{\circ} \mathrm{C}$ is shown in Fig. 2. 
The fraction transformed at time $t, f=\{\rho(0)-\rho(t)\} \mid$ $\{\rho(0)-\rho(\infty)\}$, is plotted against the aging time as shown in Fig. 3. $\quad \rho(0)$ is the resistivity which should be measured immediately after quenching, but since this measurement is impossible, $\rho(0)$ is determined graphically. $\rho(0)$ is obtained by extrapolating the aforementioned linear portion to $0.1 \mathrm{~min}$. Total changes in resistivity $\{\rho(0)-\rho(\infty)\}$, obtained during the aging in liquid nitrogen, liquid argon or liquid oxygen agree with each other. Provided that the specimens contain the same initial concentration of solute hydrogen and their change in resistivity is controlled by a single process, an activation energy can be

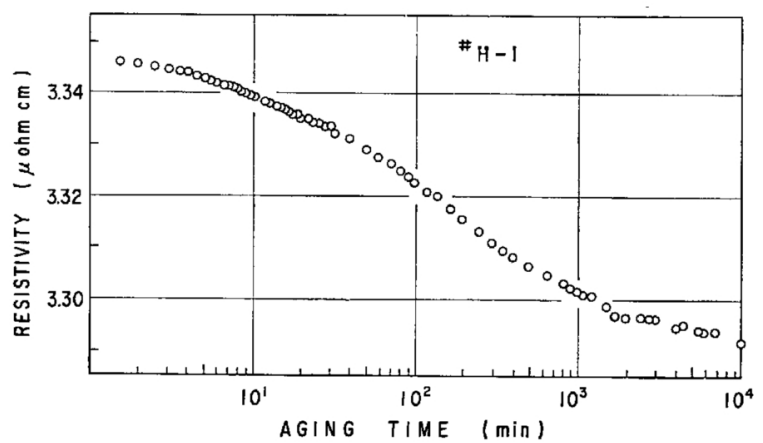

Fig. 2 Isothermal aging curve of niobium -0.8 at $\%$ hydrogen alloy at $-196^{\circ} \mathrm{C}$, after $1 \mathrm{~min}$ pulse-annealing at $-8 \tilde{5}^{\circ} \mathrm{C}$

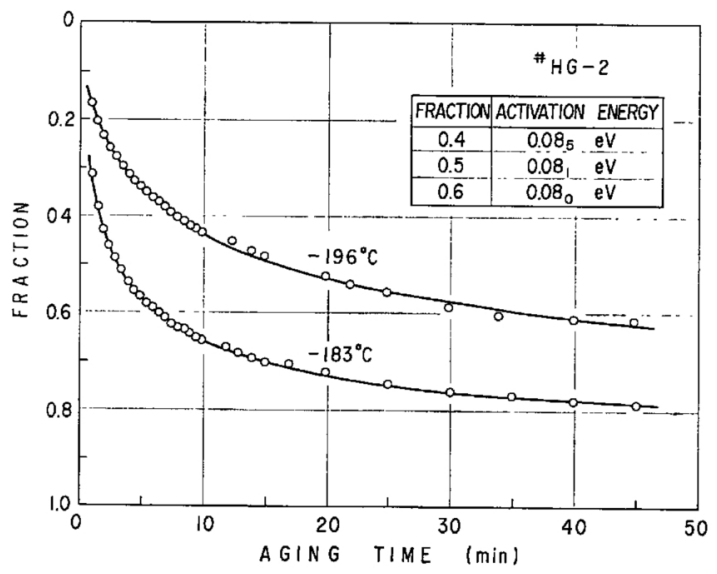

Fig. 3 Fractional change in resistivity during the isothermal aging of niobium-2.8 at\% hydrogen alloy at $-196^{\circ} \mathrm{C}$ and $-183^{\circ} \mathrm{C}$. Activation energy obtained by crosscut method is given in table

calculated by the cross-cut method (7). The activation energy of $0.8 \mathrm{eV}$ is obtained at the fraction of $0.4,0.5$ or 0.6 as given in Fig. 3. The activation energy can also be obtained by the slope-change method ${ }^{(8)}$. The specimens pulse-annealed at $-85^{\circ} \mathrm{C}$ for 1 min were subjected to the aging sequence of $-196^{\circ} \mathrm{C} \rightarrow-186^{\circ} \mathrm{C}$ as shown in Fig. 4. When the decrease in resistivity of the specimens in liquid nitrogen reached a range of fractions between 0.4 and 0.6 , the specimens were transferred to the bath of liquid argon as quickly as possible. The latter method yields an activation energy of $0.11 \pm 0.01 \mathrm{eV}$, in good agreement with the

(7) W. E. Parkins, G. J. Dienes and F. W. Brown : J. Appl. Phys., 22 (1951), 1012.

(8) R. A. Dugdale : Phil. Mag., 43 (1952), 912. value obtained by the cross-cut method within an experimental error.

Many investigators have used the following equation to describe the diffusion-controlling growth of precipitates from solid solution, $-\log (1-f)=K t^{n}$, where $t$ is the aging time, $n$ is the time exponent and $K$ is constant ${ }^{(9)}$. The isothermal aging curve is replotted in $\log \cdot \log 1 /(1-f)$ versus $\log (t)$ as shown in Fig. 5 and the time exponent is obtained as $1 / 3$.

The order of reaction in the process can be estimated by the method reported by Fujita and Damask ${ }^{(10)}$ and it shows a monotonic decrease from about 6 to 1 during the process.

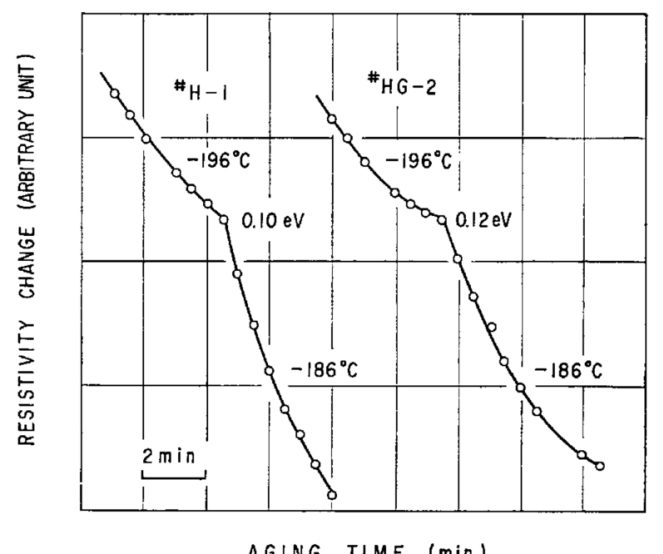

Fig. 4 Activation energy obtained by slope-change method. Decrease in resistivity of niobium-0.8at\% hydrogen ( $\$ \mathrm{H}-1)$ and niobium-2.8 at\% hydrogen ( $\$ \mathrm{HG}-2$ ) alloys by the aging sequence of $-196^{\circ} \mathrm{C} \rightarrow-186^{\circ} \mathrm{C}$

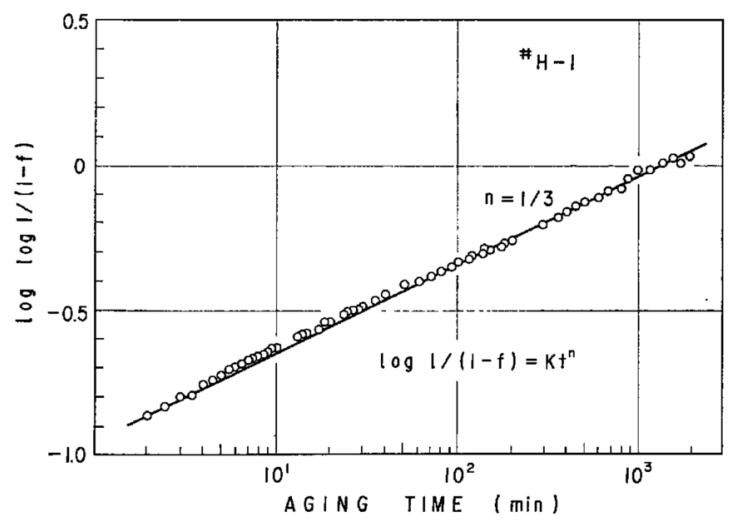

Fig. 5 Replotting of isothermal aging curve of niobium -0.8 at\% hydrogen alloy in $\log \cdot \log 1 /(1-f)$ versus $\log t$

\section{Mechanical properties}

Niobium- 0.8 at\% hydrogen alloy and hydrogen-free niobium were used in tensile tests. The typical stressstrain curves obtained after quench-aging at $-196^{\circ} \mathrm{C}$ are shown in Fig. 6. There is a marked difference in flow stress between the alloy and hydrogen-free niobium. The decrease in flow stress of niobium- -0.8 at\% hydrogen alloy was observed with the aging time as shown in Fig. 6.

(9) H. K. Hardy and T. J. Heal : Report on Precipitation, Progress in Metal Physics, 5 (1954), 143, Pergamon Press Ltd., London.

(10) F. E. Fujita and A. C. Damask : Acta Met., 12 (1964), 331. 
As the hydrogen content increased, the ductility was found to decrease practically to zero percent for niobium-4.9 at\% hydrogen alloy at $25^{\circ} \mathrm{C}$. The reproducible stress-strain curves of the alloys containing hydrogen above 2.8 at\% were hardly obtained, because of crack formation. Consequently, it was impossible to study the effect of the quench-aging on the mechanical properties of these alloys.

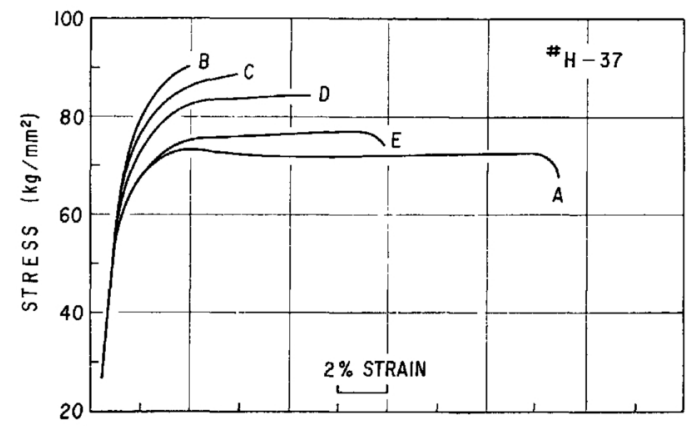

Fig. 6 Typical stress-strain curves of hydrogen-free niobium (A) and niobium -0.8 at\% hydrogen alloy $(B, C, D$ and $\mathrm{E}$ ) at $-196^{\circ} \mathrm{C}$. Quenched at $-196^{\circ} \mathrm{C}$ from $25^{\circ} \mathrm{C}$ and aged for $12 \mathrm{sec}(\mathrm{B}), 24 \mathrm{sec}(\mathrm{C}), 1 \mathrm{~min}(\mathrm{D})$ and $100 \mathrm{~min}(\mathrm{E})$ at $-196^{\circ} \mathrm{C}$ before stretching

\section{Discussion}

In the differential resistometric analyses, the heating-cooling hysteresis examined in niobium-2.8 at\% hydrogen alloy is so small that the equilibrium seems to be kept during the heating process. The differences in resistivity between alloys and hydrogen-free niobium become constant above $0 \pm 2^{\circ} \mathrm{C}$ in niobium- 0.8 at\% hydrogen alloy or $25 \pm 2^{\circ} \mathrm{C}$ in niobium-2.8 at\% hydrogen alloy. These temperatures indicated by the arrows in Fig. 1 are considered to lie on the solid solubility curve in the $\mathrm{Nb}-\mathrm{H}$ phase diagram. The solid solubility of hydrogen in niobium can be calculated from the above results and is given by the following equation; in $H$ (at\%) $=(14.7 \pm 0.2)-(8050 \pm$ 100)/RT, where $H$ (at\%) is the solid, solubility at temperature $T^{\circ} \mathrm{K}$ and $R$ is the gas constant. The solid solubility obtained in the present work is less than that of the phase diagram proposed by Walter and Chandler ${ }^{(5)}$.

The resistivity increment by the addition of hydrogen is about $0.75 \mu \Omega \mathrm{cm} / \mathrm{at} \%$ hydrogen as calculated from the curve of niobium- 0.8 at\% hydrogen alloy above $0^{\circ} \mathrm{C}$ in Fig. 1. This agrees well with the result of Borgucci and Verdini( ${ }^{(1)}$. A part of the difference in resistivity between hydrogen-free niobium and niobium-2.8 at\% hydrogen alloy is caused by the contaminants such as oxygen and nitrogen. Niobium -2.8 at\% hydrogen alloy was prepared by the gas exposure method and the contamination was about $100 \mathrm{ppm}$. It was reported that the resistivity increment by the addition of oxygen ${ }^{(11)}$ or nitrogen ${ }^{(12)}$ was about $4.1 \mu \Omega \mathrm{cm} /$ at\% of these elements above $0^{\circ} \mathrm{C}$. The resistivity increment due to the presence of

(11) E. Gebhardt and R. Rothenbacher : Z. Metallk., 54 (1963), 663.

(12) W. Dürrschnabel and G. Hörz : Naturwiss., 22 (1963), 687. hydrogen, oxygen and nitrogen in niobium-2.8 at\% hydrogen alloy is calculated as $2.4 \mu \Omega \mathrm{cm}$ from the values described above. This agrees with the difference in resistivity between hydrogen-free niobium and niobium-2.8 at\% hydrogen alloy above $25^{\circ} \mathrm{C}$ as shown in Fig. 1.

Increasing of $\Delta \rho$ is observed above $-160^{\circ} \mathrm{C}$ as shown in Fig. 1 and it is considered that hydride dissolves continuously in niobium above this temperature. In the experiments of isothermal aging, the specimens were first pulse-annealed at $-85^{\circ} \mathrm{C}$. At this temperature, hydride and solute hydrogen could coexist in the specimens. The decrease in resistivity during the quench-aging at $-196^{\circ} \mathrm{C}$ can be mainly attributed to the solute depletion and the growth of precipitates of hydride.

The apparent activation energy calculated from the change in resistivity is $0.10 \pm 0.02 \mathrm{eV}$ as given in Figs. 3 and 4. Zamir and $\operatorname{Cotts}^{(3)}$ used the nuclear magnetic resonance method and found that the activation energy for the diffusion of hydrogen in niobiumhydrogen solid solution alloy was $0.16 \mathrm{eV}$. This fairly agrees with the results of the present work. However, the present result disagrees with those of the study by Albrecht et al. (4) who used the gas absorption method. The activation energy obtained by NMR or the resistometric study in the present work is independent of surface reaction. The activation energy of about. $0.1 \mathrm{eV}$ is the reliable value for the diffusion of hydrogen in niobium metal.

Any loss of hydrogen from the solid solution matrix resulted in a decrease in resistivity. In some alloys, the decrease in resistivity was observed in the precipitation of hydride at low temperatures below $0^{\circ} \mathrm{C}$. Allen et al.(13) studied the process of hydride precipitation in $a$-titanium by the resistometric technique in the temperature range from $-100^{\circ}$ to $+100^{\circ} \mathrm{C}$ and observed that the monotonic decrease in resistivity was accompanied with the precipitation of hydride. Westlake ${ }^{(14)}$ recently observed a decrease in electrical resistivity at $-43^{\circ} \mathrm{C}$ in vanadium- 0.5 at\% hydrogen alloy and suggested that it might be attributed to the precipitation of hydride in vanadium metal during cooling.

The time exponent in the precipitation of hydride is $1 / 3$ in the present work as given in Fig. 5 . Lement and Cohen ${ }^{(15)}$ pointed out that the time exponent could be $1 / 3$ in the precipitation of the plate-like $\varepsilon$-carbide from $\mathrm{Fe}-\mathrm{C}$ martensite on the basis of the attraction model governing the flow of carbon atoms by parallel dislocations. In the present work, the process involved can be likewise considered as the segregation of solute hydrogen to the plate-like hydride. Niobium hydride was suggested to grow in the form of platelets ${ }^{(6)}$.

The order of reaction in the initial stage is obtained as about 6 and it decreases gradually to 1 with the aging time. The decrease in the order of reaction

(13) R. P. Allen, R. Targart and D. H. Polonis : Acta Met., 14 (1966), 741.

(14) D. G. Westlake : Phil. Mag., 16 (1967), 905.

(15) B. S. Lement and M. Cohen : Acta Met., 4 (1956), 469. 
during the process is interpreted as the concentration effect pointed out by Fujita and Damask(10) who studied the decrease in resistivity in the aging process of iron-carbon alloy after irradiation.

The flow stress of the alloy is higher than that of hydrogen-free niobium and it decreases during the aging at $-196^{\circ} \mathrm{C}$ as shown in Fig. 6 . In precipitationhardening alloys, it has been well known that an increase in flow stress is observed at the initial stage of aging. However, the rate of precipitation in the niobium-hydrogen alloy is so rapid that it is difficult to observe an initial increase in flow stress. The decrease in flow stress during the aging can be attributed to the growth of hydride precipitates and the decrease in the number of precipitates in the course of overaging.

\section{Conclusions}

The aging behavior in niobium-hydrogen alloys below room temperature was investigated by the measurements of electrical resistivity and flow stress, and the following points were established.

(1) The decrease in electrical resistivity is observed in niobium-hydrogen alloys quenched and aged at low temperatures in the range of $-183^{\circ}$ to $-196^{\circ} \mathrm{C}$. This is attributed to the hydride precipitation at these temperatures.

(2) The analyses of the isothermal aging curves obtained in this temperature range, yield an activation energy of $0.10 \pm 0.02 \mathrm{eV}$ and the time exponent of $1 / 3$ for the process of the hydride precipitation.

(3) The flow stress of the alloy quench-aged at. $-196^{\circ} \mathrm{C}$ is higher than that of hydrogen-free niobium. The decrease in the flow stress during the aging occurs, probably due to the overaging.

\section{Acknowledgments}

We wish to express our gratitude to Professor J. Takamura of Kyoto University, Dr. R. Watanabe and. Mr. S. Matsuo for their valuable discussions and comments. Thanks are also due to Dr. H. Kimura for his. encouragement and continuous interest. 